\title{
Influence of Phasic and Tonic Dopamine Release on Receptor Activation
}

\author{
Jakob K. Dreyer, ${ }^{1}$ Kjartan F. Herrik, ${ }^{2}$ Rune W. Berg, ${ }^{1}$ and Jørn D. Hounsgaard ${ }^{1}$ \\ ${ }^{1}$ Department for Neuroscience and Pharmacology, University of Copenhagen, DK-2200 Copenhagen, Denmark, and ${ }^{2} \mathrm{H}$ Lundbeck A/S, Department of \\ Neurophysiology, DK-2500 Valby, Denmark
}

Tonic and phasic dopamine release is implicated in learning, motivation, and motor functions. However, the relationship between spike patterns in dopaminergic neurons, the extracellular concentration of dopamine, and activation of dopamine receptors remains unresolved. In the present study, we develop a computational model of dopamine signaling that give insight into the relationship between the dynamics of release and occupancy of $D_{1}$ and $D_{2}$ receptors. The model is derived from first principles using experimental data. It has no free parameters and offers unbiased estimation of the boundaries of dopaminergic volume transmission. Bursts primarily increase occupancy of $D_{1}$ receptors, whereas pauses translate into low occupancy of $D_{1}$ and $D_{2}$ receptors. Phasic firing patterns, composed of bursts and pauses, reduce the average $\mathrm{D}_{2}$ receptor occupancy and increase average $\mathrm{D}_{1}$ receptor occupancy compared with equivalent tonic firing. Receptor occupancy is crucially dependent on synchrony and the balance between tonic and phasic firing modes. Our results provide quantitative insight in the dynamics of volume transmission and complement experimental data obtained with electrophysiology, positron emission tomography, microdialysis, amperometry, and voltammetry.

\section{Introduction}

Dopaminergic (DA) neurons in ventral tegmental area and substantia nigra pars compacta are key players in reinforcement learning, motivation, and motor output (Graybiel et al., 1994; Cagniard et al., 2006). Most of these neurons are spontaneously active with firing patterns that range from regular pacemaker firing (Grace and Bunney, 1984a) to burst firing (Grace and Bunney, 1984b). In addition, rewards and salient events induce brief bursts, whereas adverse events tend to decrease activity (Schultz, 1998; Redgrave and Gurney, 2006). Loss of dopaminergic neurons in substantia nigra leads to Parkinson's disease (Galvan and Wichmann, 2008), addictive substances such as cocaine and amphetamine modulate the reuptake of dopamine (John and Jones, 2007), and treatments of schizophrenia and attention deficit hyperactivity disorder involve regulations of the dopamine system (Carlsson, 2001; Engert and Pruessner, 2008).

Tonic and phasic dopamine release has been related to particular behavioral states (Robinson et al., 2002; Tsai et al., 2009; Zweifel et al., 2009). However, the crucial relation between the multiple timescales of firing patterns and postsynaptic dopamine receptor activation has not been established. Clearly, the spatiotemporal patterns of receptor activation will depend on the complex dynamics of release, diffusion, and uptake in ways that are not presently accessible to experimental analysis. Therefore, we used computer models to simulate how population activity of

Received April 14, 2010; revised July 27, 2010; accepted Aug. 23, 2010.

This work was supported by Danish Medical Research Council, The Novo Nordisk Foundation, and The Lundbeck Foundation.

Correspondence should be addressed to Jakob K. Dreyer, Department for Neuroscience and Pharmacology, University of Copenhagen, Blegdamsvej 3, 12.5, DK-2200 Copenhagen, Denmark. E-mail: jakobdr@sund.ku.dk.

DOI:10.1523/JNEUROSCI.1894-10.2010

Copyright $\odot 2010$ the authors $\quad 0270-6474 / 10 / 3014273-11 \$ 15.00 / 0$ dopaminergic neurons affects dopamine levels and receptor occupancy in dorsal striatum.

We present a unifying model of dopamine volume transmission that encompasses both tonic and phasic release and activation of receptors. The model is derived from first principles using physiological and anatomical data and validated by comparison with published experimental observations. Using this model, we first analyzed the impact of isolated bursts and pauses (responses to external stimuli). Bursts (synchronized transient increases in firing rate) primarily increased $D_{1}$ receptor occupancy, whereas $\mathrm{D}_{2}$ receptor occupancy was less affected. Pauses decreased occupancy of both receptors. In both cases, the modulation was linearly dependent on the duration of the transient. We then analyzed different types of spontaneous activity observed in dopamine neurons (regular firing patterns vs spontaneous bursts, followed by pauses). We found that bursts and pauses reduce the average occupancy of $\mathrm{D}_{2}$ receptors by $>40 \%$ compared with tonic firing. At the same time, the average occupancy of $\mathrm{D}_{1}$ receptors was slightly increased. Thus, the different firing patterns observed during spontaneous activity of dopamine neurons influence the balance between $D_{1}$ and $D_{2}$ receptordependent pathways.

We also validate simplified mathematical expressions used to interpret electrically stimulated dopamine release and extracellular dopamine levels (Wightman and Zimmerman, 1990; Wu et al., 2001; Venton et al., 2003).

\section{Materials and Methods}

Numerical values of parameters are given in Table 1.

Our model describes extracellular volume transmission of dopamine based on experimental results from the dorsal striatum. The simulations describe the spatiotemporal distribution of dopamine in a cubic simulation space representing an idealized cubic block of tissue (Arbuthnott 


\begin{tabular}{|c|c|c|c|}
\hline Variable & Description & Reference/expression & Value \\
\hline$\alpha$ & Volume fraction of extracellular space & Nicholson, 1995 & 0.21 \\
\hline$D^{*}$ & Effective dopamine diffusion constant (including correction for tortuosity) & Nicholson, 1995; Rice and Cragg, 2008 & $322 \mu \mathrm{m}^{2} / \mathrm{s}$ \\
\hline$n_{\text {term }}$ & Number of terminals per dopaminergic axon & Arbuthnott and Wickens, 2007 & 370000 \\
\hline$V_{\text {axon }}$ & Volume of axonal arbor & Matsuda et al., 2009 & $0.54 \mathrm{~mm}^{3}$ \\
\hline$\rho_{1}$ & Density of terminals on a single axon & $n_{\text {term }} / V_{\text {axon }}$ & $0.001 \mu \mathrm{m}^{-3}$ \\
\hline$\rho$ & Total density of dopamine terminals in striatum & Doucet et al., 1986 & $0.104 \mu \mathrm{m}^{-3}$ \\
\hline$I_{\mathrm{DA}}$ & Tissue content of dopamine in striatum & Bannon et al., 1981 & $9.3 \mu \mathrm{g} / \mathrm{cm}^{3}$ \\
\hline$R$ & Fraction of terminal content released per action potential & Gubernator et al., 2009 & $0.05 \% \%^{a}$ \\
\hline$N_{0}$ & Number of dopamine molecules released during vesicle fusion & Pothos et al., 1998 & 3000 \\
\hline$P_{r}$ & Vesicle release probability & Equation 1 (see text) & $6 \%$ \\
\hline$V_{\max }$ & Michaelis-Menten uptake parameter & Bergstrom and Garris, 2003 & $4.1 \mu \mathrm{m} / \mathrm{s}$ \\
\hline$K_{m}$ & Michaelis-Menten uptake parameter & Bergstrom and Garris, 2003 & $0.21 \mu \mathrm{M}$ \\
\hline $\mathrm{EC}_{50}^{1}$ & Affinity of $D_{1}$ receptor & Rice and Cragg, 2008 & $1 \mu \mathrm{M}$ \\
\hline $\mathrm{EC}_{50}^{2}$ & Affinity of $\mathrm{D}_{2}$ receptor & Rice and Cragg, 2008 & $10 \mathrm{~nm}$ \\
\hline$N_{\max }$ & Total number of neurons projecting into simulation space & $\rho / \rho_{1}$ & 100 \\
\hline$N_{\mathrm{ph}}$ & Number of neurons engaged in phasic release & $N_{\text {to }}+N_{\text {ph }} \leq N_{\max }$ & $0-N_{\max }^{b}$ \\
\hline$N_{\text {to }}$ & Number of neurons engaged in tonic release & $N_{\text {to }}+N_{\text {ph }} \leq N_{\max }$ & $0-N_{\max }^{b}$ \\
\hline
\end{tabular}

Note that some parameters are combined to determine $\rho_{1}$ and $P_{r}$ and require conversion to different units.

${ }^{a} G$ Gubernator et al. (2009) find $R=0.03-0.07 \%$, for stimulation frequencies between 20 and $4 \mathrm{~Hz}$.

${ }^{b}$ Different values of $N_{\text {ph }}$ and $N_{\text {to }}$ are tested in this study.

and Wickens, 2007) with uniform distribution of receptors and transporters. Dopamine was released in quanta from distinct randomly located terminals driven by firing of external dopaminergic neurons (see Fig. 1).

Number of terminals, release probability, and number of external neurons. The simulation space was defined as a cube of volume $15,000 \mu \mathrm{m}^{3}$ (24.7 $\mu \mathrm{m}$ on each side). The size of the simulation space was set to be substantially larger than the typical extracellular diffusion distance of dopamine (Gonon et al., 2000; Venton et al., 2003). In simulation space, there were 1500 distinct randomly located release sites (Doucet et al., 1986). On average, a single DA neuron connects to 370,000 terminals (Arbuthnott and Wickens, 2007), which are distributed inside a $0.5 \mathrm{~mm}^{3}$ axonal arbor (Matsuda et al., 2009). From these data, we determined the density of terminals connecting to a single axon, $\rho_{1}=0.001 \mu \mathrm{m}^{-3}$. To keep this density constant, we assigned 15 terminals to each axon projecting to our simulation space giving $N_{\max }=$ 100 as the maximal number of dopaminergic axons projecting into the simulation space.

The release probability determines the likelihood that an action potential evokes vesicular release from a terminal. The release probability is determined as

$$
P_{r}=\frac{I_{\mathrm{DA}} R}{\rho N_{0}}=6 \%,
$$

where $I_{\mathrm{DA}}$ is the tissue content of dopamine (Bannon et al., 1981), $R$ is the average fraction of terminal contents released per action potential (Gubernator et al., 2009), $\rho$ is total density of dopamine release sites (Doucet et al., 1986), and $N_{0}$ is the number of dopamine molecules released in successful vesicle fusion (Pothos et al., 1998) (for numerical values, see Table 1 ).

Definition of firing patterns. Dopamine neurons signal by phasic and tonic transmission (Goto et al., 2007). To investigate these fundamental behaviors of the dopamine neurons systematically, we defined tonic and phasic firing patterns and assigned them to different groups of neurons. Tonic firing was defined as random Poisson spikes at an average rate of 4 Hz. Bursts were defined as transient increases in firing rate using Poisson spikes with average firing rate of $20 \mathrm{~Hz}$. The duration of the burst transients was selected to give one to seven spikes in the bursts on average (see Figs. 2, 3). Alternatively, we used bursts defined as a sequence of regular spikes. The difference in average dopamine levels and occupancy of receptors between these two definitions was minimal (data not shown). Regular bursts required less simulation time and were used in timedemanding investigations (see Figs. 4, 6), when investigating the effect of intraburst frequency (see Fig. 5A), and to simulate electrically evoked spikes (see Fig. 7). Pauses were defined by the absence of firing. The duration of pauses was up to $1 \mathrm{~s}$. Bursts and pauses were shared by a variable number of neurons, but the spikes themselves were generated by independent Poisson processes. The number of these phasic neurons is denoted as $N_{\mathrm{ph}}$, and the number of tonically firing neurons is denoted as $N_{\text {to }}$.

We examined the consequences of varying combinations of bursts, pauses, and tonic firing. In the analysis of isolated transient changes in firing rate, we investigated the effect of tonic firing interrupted by bursts or pauses of varying duration.

In the analysis of phasic signaling in spontaneous firing, we investigated the effect of mixed population activity with firing patters composed of bursts, pauses, and tonic firing. We divided the neurons into two groups: in $N_{\mathrm{ph}}$ phasically firing neurons, synchronous periods of bursts alternated with pauses (Grace and Bunney, 1984b). The duration of the bursts ( $0.25 \mathrm{~s}$ ) was set to give five spikes at $20 \mathrm{~Hz}$ average rate during bursts, and the length of the pause ( $1 \mathrm{~s}$ ) was selected to give $4 \mathrm{~Hz}$ average firing rate. Tonic firing was generated in $N_{\text {to }}$ neurons (Grace and Bunney, 1984a). We also tested the effect of lowering the total number of spontaneously active neurons (Grace and Bunney, 1979). For example, when $N_{\mathrm{ph}}=30$ and $N_{\mathrm{to}}=50$, the difference between $N_{\max }=100$ and $\left(N_{\mathrm{ph}}+N_{\mathrm{to}}\right)$ implies 20 inactive neurons.

The average firing rate of each dopamine neuron was $4 \mathrm{~Hz}$ except in Figure 7 where varying tonic firing rate was used to generate various basal levels of dopamine.

Additional details concerning the implementation are given below.

Integration of spatiotemporal distribution of dopamine. The tissue was modeled as a porous medium with extracellular volume fraction and tortuosity as described by Nicholson (1995). The simulation space used periodic boundary conditions. The dopamine concentration at position $\mathbf{r}$ and at time $t$ is written as $C(\mathbf{r}, t)$. For each step in time, the time evolution of $C(\mathbf{r}, t)$ was calculated by integrating

$$
\frac{\partial C(\mathbf{r}, t)}{\partial t}=\sum_{j}^{N_{\max }} \sum_{\left\{t_{j n}\right\}} \Delta C_{j}(\mathbf{r}) \partial\left(t-t_{j n}\right)+D^{\star} \nabla^{2} C(\mathbf{r}, t)-\frac{V_{\max } C(\mathbf{r}, t)}{K_{m}+C(\mathbf{r}, t)} .
$$

Here, the first term describes the release from spiking activity of each of the neurons with $\left\{t_{j n}\right\}$ giving the set of spikes for neuron $j$. The subscript $n$ is the spike number of neuron $j$. Here $\Delta C_{j}(\mathbf{r})$ represents the unique spatial release pattern from the terminals of neuron $j$ (defined below) and $\delta\left(t-t_{j n}\right)$ is the Dirac $\delta$ function representing the release at time $t_{j n}$. The 
effect of the $\delta$ function is a sudden increase in dopamine concentration at the releasing terminals. Thus, the double sum was evaluated as follows. During the simulation, we evaluated whether any of the neurons were spiking within the next time step. If a spike occurs for neuron number $j$, the spatial concentration of dopamine was updated by an increment

$$
\Delta C_{j}(\mathbf{r})=\frac{N_{0}}{\alpha N_{A}\left(2 \pi s^{2}\right)^{3 / 2}} \sum_{i=1}^{m} \Theta\left(P_{r}\right) \exp \left(-\frac{\left(\mathbf{r}-\mathbf{r}_{i j}\right)^{2}}{2 s}\right) .
$$

The coefficient $\alpha$ is a correction for the fraction of the extracellular part of tissue (Nicholson, 1995), and $N_{A}$ is Avogadros constant. The sum represents the probabilistic release from $m=15$ terminals. $\Theta\left(P_{r}\right)$ is a stochastic variable equal to 1 with probability $P_{r}$ and 0 otherwise where $P_{r}$ is the release probability. The parameter $s=150 \mathrm{~nm}$ represents the approximate diameter of a dopaminergic terminal (Garris et al., 1994), and $\mathbf{r}_{i j}$ is the location of terminal $i$ on neuron $j$. Equation 3 represents the spatial release pattern of the terminals of neuron $j$. If the release of more neurons coincided in the same time step, an increment was calculated for each neuron and added within the same time step.

The second term in Equation 2 describes the time evolution attributable to diffusion. Here $D^{\star}$ is the effective diffusion constant and $\nabla^{2}$ is the three-dimensional Laplacian operator. The third term is the uptake term and exhibits Michaelis-Menten-type kinetics.

Equation 2 was integrated numerically using finite differences. The spatial resolution was $d r=0.60 \mu \mathrm{m}$, and the time step was $d t=1.610^{-4} \mathrm{~s}$. Initially simulations at higher resolution, $d r=0.15 \mu \mathrm{m}$ and $d t=10^{-5} \mathrm{~s}$, were performed with nearly identical results (data not shown).

In each time step, the instantaneous occupancy of receptors was calculated using Equation 12 (see below).

Michaelis-Menten uptake model. We also describe the time development of the spatial average of the extracellular dopamine concentrations, $C(t)$. Here we assume that $C(t)$ evolves as a competition between release from terminals and Michaelis-Menten reuptake (Wightman and Zimmerman, 1990). This can be described as

$$
\frac{d C}{d t}=I(t)-\frac{V_{\max } C(t)}{K_{m}+C(t)}
$$

The release $I(t)$ represents the dopamine release from spikes in the neurons contributing to the local dopamine level. Effectively, $C(t)$ is raised by a generic amount,

$$
\Delta C=\rho_{1} \frac{P_{r} N_{0}}{\alpha N_{A}},
$$

with each action potential in one of the contributing neurons.

We consider the dopamine level to be composed of a phasic component from a pool of $N_{\mathrm{ph}}$ neurons with synchronized activity and a tonic component from $N_{\text {to }}$ tonically active neurons. The dopamine release is then modeled as $I(t)=I_{\mathrm{ph}}(t)+I_{0}$, where $I_{\mathrm{ph}}(t)$ represents release from the synchronized neurons and $I_{0}$ is a constant rate of release from the nonsynchronized neurons. The amplitude of a transient of a single synchronized spike in $N_{\mathrm{ph}}$ neurons is $N_{\mathrm{ph}} \Delta C$. The value of $I_{0}$ is given by

$$
I_{0}=\nu N_{\mathrm{to}} \Delta C
$$

where $\nu$ is the average firing rate of the nonsynchronized neurons. In steady state, the background level $C_{0}$, is given as (Chen, 2005)

$$
C_{0}=\frac{K_{m} I_{0}}{V_{\max }-I_{0}} .
$$

Note that Equation 7 is valid only when $I_{0}<V_{\max }$. If this condition is not met, steady state cannot be reached and the dopamine level will constantly rise.

The time development of transients relative to $C_{0}$ is given as

$$
\frac{d C_{\mathrm{ph}}}{d t}=I_{\mathrm{ph}}=\frac{V^{\prime} C_{\mathrm{ph}}(t)}{K^{\prime}+C_{\mathrm{ph}}(t)} .
$$

The parameters

$$
V^{\prime}=V_{\max }-I_{0}
$$

and

$$
K^{\prime}=K_{m}\left(1+\frac{I_{0}}{V_{\max }-I_{0}}\right),
$$

are apparent uptake constants (Chen, 2005). The apparent time constant, $\tau^{\prime}=K^{\prime} / V^{\prime}$, depends on the tonic activity as

$$
\tau^{\prime}=\tau\left(1+\frac{I_{0}}{V_{\max }-I_{0}}\right) \approx \tau\left(1+\frac{2 I_{0}}{V_{\max }-I_{0}}\right) .
$$

Thus, the effective time constant is increasing as function of $I_{0}$. For low values of $I_{0}$, the dependence is approximately linear.

Calculating occupancy and postsynaptic activation. Of the five known dopamine receptors, we focus on low-affinity $\mathrm{D}_{1}$ receptors $\left(\mathrm{EC}_{50}^{1}=1 \mu \mathrm{M}\right)$ and high-affinity $\mathrm{D}_{2}$ receptors $\left(\mathrm{EC}_{50}^{2}=0.01 \mu \mathrm{M}\right.$ ) (Rice and Cragg, 2008).

We assumed uniform distribution of receptors and transporters in the extracellular space. The spatial average of the occupancy of receptors of type $i$ at time $t$ was found by integration of $C(\mathbf{r}, t)$ over the simulation space:

$$
D_{i}(t)=\frac{1}{\Omega} \int_{\Omega} \frac{C(\mathbf{r}, t)}{\mathrm{EC}_{50}^{i}+C(\mathbf{r}, t)} d \mathbf{r}
$$

Here $|\Omega|$ is the volume of the simulation space and $\mathrm{EC}_{50}^{\mathrm{i}}$ is the affinity of receptor $i$. The index $i$ may represent any of the different types of receptors: $\mathrm{D}_{1}$ or $\mathrm{D}_{2} . D_{i}(t)$ expresses the fraction of the occupied receptors relative to the total number of receptors available. Thus, $D_{2}(t)=100 \%$ means that all $\mathrm{D}_{2}$ receptors in the integration volume are occupied by the dopamine at time $t$.

Little is known about the mapping between occupancy of dopamine receptors and turnover of the postsynaptic signaling cascade. As a conservative assumption, we consider the postsynaptic effect of the dopaminergic activity to reflect the time integrated occupancy of receptors (Hille, 1992). However, to complete the picture, we also considered the possibility that activation of the postsynaptic signaling cascade occurs once the local dopamine levels are sufficiently high to reach a threshold occupancy. In this activation paradigm, we quantified the activity as the volume fraction of simulation space where $C(\mathbf{r}, t) \geq \mathrm{EC}_{X}^{i}$, where $X$ indicates the occupancy and $i$ indicates the receptor. $\mathrm{EC}_{X}^{i}$ was estimated from $\mathrm{EC}_{50}^{i}$ assuming noncooperative response.

Time-averaged occupancy of receptors was determined as the time average of Equation 12:

$$
\left\langle D_{i}\right\rangle=\frac{1}{T_{\max }} \int_{0}^{T_{\max }} D_{i}(t) d t .
$$

Because our model includes stochastic release and firing, averaging was used to reduce noise. In averages of periodic signals, $T_{\max }$ was equal to an integer number of repetitions of the burst-pause pattern and the first burst-pause cycle was omitted.

Simulations and analysis was performed in Matlab 7.6.

\section{Results}

\section{Synchronized release cause global saturation of $D_{2}$ receptors} but local saturation of $D_{1}$ receptors

Dopamine is released in discrete quanta from distinct sites. Thus, dopamine is heterogeneously distributed shortly after release, and regions near release sites experience temporal saturation of receptors and uptake. We first investigated the impact of temporal saturation by examining the interplay between release, diffusion, and uptake on dopamine concentration and dopamine 
receptor occupancy. We estimated the degree of saturation of dopamine receptors by measuring the volume fraction where $C(\mathbf{r}, t) \geq \mathrm{EC}_{50}$ of the two receptors.

We considered the spatiotemporal evolution of the saturated volume after a single synchronized spike in 20 neurons (Fig. 1, right) (supplemental Movie S1, available at www.jneurosci.org as supplemental material).

Immediately after the release, dopamine was concentrated around the release sites. After $2 \mathrm{~ms}$, the concentration of dopamine exceeded $1 \mu \mathrm{M}\left(\mathrm{EC}_{50}^{1}\right)$ in the neighborhood of the release sites (Fig. 1, right, red areas). However, the localized saturation of $\mathrm{D}_{1}$ receptors lasted only milliseconds. The regions of high $\mathrm{D}_{2}$ occupancy evolved on a slower timescale and filled a larger part of simulation space [blue surface in Fig. 1 indicates the boundary where $C(\mathbf{r}, t) \geq$ $\left.\mathrm{EC}_{50}^{2}\right]$. After $\sim 60 \mathrm{~ms}$ of the release, the concentration of dopamine was everywhere lower than $\mathrm{EC}_{50}^{2}$ (supplemental Fig. S1, blue dashed line, available at www.jneurosci.org as supplemental material).

We then added a second synchronized release from the same neurons $50 \mathrm{~ms}$ after the first release (supplemental Movie S2, available at www.jneurosci.org as supplemental material). Now the saturated volume for $\mathrm{D}_{2}$ receptors continued to expand and eventually covered the entire simulation space. In contrast, saturation of $D_{1}$ receptors by the second spike was still localized and of short duration (supplemental Fig. S1, solid red line, available at www.jneurosci.org as supplemental material).

Thus, a few synchronized spikes from a subset of the available neurons could occupy $>50 \%$ of the $\mathrm{D}_{2}$ receptors in the entire terminal field, whereas $50 \% \mathrm{D}_{1}$ receptor activation was only achieved within a radius of $1 \mu \mathrm{m}$ of the release sites. These observations are in accord with the analyses of single terminals made by Cragg and Rice (Cragg and Rice, 2004; Rice and Cragg, 2008).

\section{Isolated bursts and pauses influence $D_{1}$ and $D_{2}$ receptors}

We then explored the effect of firing patterns on dopamine receptors under more realistic conditions with many neurons active at the same time. We first examined the effects of isolated bursts and pauses as observed in reinforcement learning. Positive reinforcement (rewards) is associated with increased firing in dopamine neurons, whereas negative reinforcement (omission of expected rewards and adverse events) is associated with pauses (Schultz, 1998). It has also been demonstrated that the magnitude of the bursts and pauses in primates is correlated with the magnitude of the reward prediction error (Bayer et al., 2007). We therefore assessed the effect of such modulations in the firing of dopamine neurons on dopamine levels and occupancy of $\mathrm{D}_{1}$ and $\mathrm{D}_{2}$ receptors.

We generated background tonic activity by assigning random uncorrelated $4 \mathrm{~Hz}$ firing to an ensemble of 100 neurons. Then, brief epochs of either increased or paused firing were imposed on the neuronal activity. In burst epochs, the firing rate during was transiently increased to $20 \mathrm{~Hz}$ (on average) for all neurons (Fig. 2A1). The duration of the epoch was selected to give bursts of different length, corresponding to one to seven spikes. During pauses, no neurons were allowed to fire; the length of the pauses was up to $1 \mathrm{~s}$ (Fig. 2A2). After the transients, the neuronal population returned to the tonic state.

Tonic activity alone gave an average \pm SEM dopamine level of $37 \pm 1.2 \mathrm{~nm}$. Burst epochs gave transients in the average volumeaveraged dopamine level in the range from 100 to $300 \mathrm{nM}$, depending on the average number of spikes in the burst (Fig. 2B1). During pauses, the dopamine level decayed to zero within $0.2 \mathrm{~s}$ (Fig. 2 B2).

We then considered the concurrent volume-averaged occupancy of $D_{1}$ and $D_{2}$ receptors. The occupancy of $D_{1}$ receptors followed the dopamine transients, i.e., transient increase or decrease in occupancy. During tonic activity, the occupancy of $\mathrm{D}_{1}$ receptors was $3.5 \%$. At the peak dopamine levels during bursts, the maximal occupancy was several-fold higher, peaking at $\sim 25 \%$ (Fig. 2C1, red line). The $\mathrm{D}_{2}$ receptors, conversely, were already $75 \%$ occupied by tonic activity alone. During bursts, the occupancy exceeded $95 \%$. Thus, bursts primarily affected $\mathrm{D}_{1}$ receptor occupancy (Fig. 2C1, compare red and blue lines).

During pauses, the occupancy of both receptors decreased. The decay was slightly faster for $\mathrm{D}_{1}$ than for $\mathrm{D}_{2}$ receptors (Fig. $2 C 2$, same colors as $C 1$ ). We quantified the area under the curve (AUC) of the occupancy. The impact of the transients was determined by the difference in AUC during transients relative to the tonic state $(\triangle \mathrm{AUC})$ (Fig. $2 \mathrm{D} 1, \mathrm{D} 2)$. For $\mathrm{D}_{1}$ receptors, $\triangle \mathrm{AUC}$ was directly proportional to the duration of the bursts, whereas there was little change in $\triangle \mathrm{AUC}$ for $\mathrm{D}_{2}$ receptors. During pauses, the $\Delta \mathrm{AUC}$ of both receptor occupancies showed a negative dependence proportional to pause duration. The decrease was slightly lower for $\mathrm{D}_{2}$ than for $\mathrm{D}_{1}$ receptors.

\section{Complex temporal receptor activation by spontaneous firing patterns}

Dopaminergic neurons also have different types of spontaneous activity. Some neurons fire spikes in a regular pacemaker-like pattern (Grace and Bunney, 1984a), whereas other dopamine neurons fire phasically, characterized by brief bursts followed by pauses (Grace and Bunney, 1984b; Hyland et al., 2002; Goto et al., 2007). Typically, the average firing rate of the different populations is similar and the fraction of spontaneously bursting neurons and the firing properties of the different populations are controlled independently (Floresco et al., 2003; Lee et al., 2004). In our investigations of spontaneous activity, we wanted to isolate the effect of firing pattern per se. Consequently, the average 

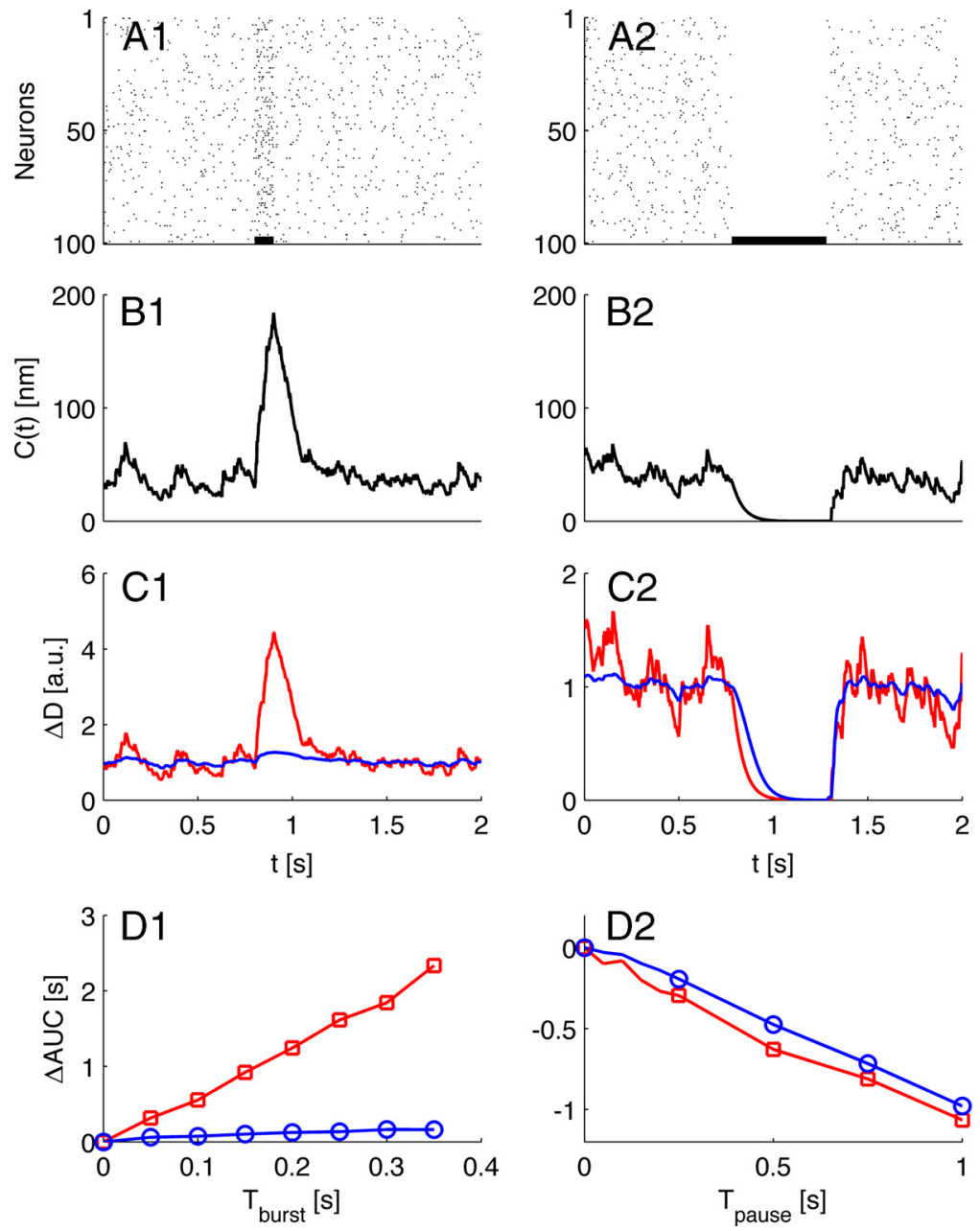

Figure 2. A1-D2, Effect of bursts and pauses on dopamine levels and receptors. Left column (A1-D1) shows results for bursts, and right column (A2-D2) shows pauses. A1, A2, Rastogram of spike activity across the population of neurons. Solid black lines near the $x$-axes indicate the duration of transients. The burst in $\boldsymbol{A} \mathbf{1}$ has two spikes on average, and the pause in $\boldsymbol{A} \mathbf{2}$ lasts $0.5 \mathrm{~s} . \boldsymbol{B 1}$, $B 2$, Concurrent volume-averaged levels of dopamine resultant of the spikes shown in $\boldsymbol{A} . \mathbf{C 1}, \mathbf{C}$, Relative impact of transients on volume-averaged occupancy of receptors. Red, $D_{1}$ receptor occupancy. Blue, $D_{2}$ receptor occupancy. The occupancies are normalized so that occupancy of the tonic activity is 1 . a.u., Arbitrary units. D1, D2, Integrated change in occupancy by transients of different length. Same colors as in $\mathbf{C}$ and $\mathbf{C}$.

firing rate of both burst firing and tonic firing neurons were the same.

We now asked how a mixture of these spontaneous firing patterns influenced dopamine levels and occupancy of receptors. A key issue here is the degree of synchrony between spontaneously firing neurons. Only a few studies have addressed this directly. In freely moving rats, Hyland et al. (2002) observed $\sim 100$ ms correlation between $26 \%$ of simultaneously recorded pairs of dopaminergic neurons. This corresponds to approximately half of the cells being loosely synchronized, in the sense that they emit bursts in overlapping time windows. Also, Vandecasteele et al. (2005) showed that, in slice preparations, tonic firing was not synchronized. Based on these observations, we allocated $N_{\mathrm{ph}}=$ 50 neurons to fire synchronized bursts, followed by pauses (Grace and Bunney, 1984b; Hyland et al., 2002). Another group of $N_{\text {to }}=50$ neurons fired nonsynchronized and randomly at 4 Hz. Burst firing consisted of $0.25 \mathrm{~s}$ epochs with $20 \mathrm{~Hz}$ average firing rate (on average, five spikes), followed by a $1 \mathrm{~s}$ pause; the average firing rate of all neurons was $4 \mathrm{~Hz}$. The burst and pause epochs of phasic neurons were coincident, but within burst epochs neurons fired independently (Fig. $3 A$ ). In this simulation, the total spike count is the same as the tonic activity in our previous study of isolated bursts and pauses.

The concurrent volume-averaged dopamine, $C(t)$, displayed rapid transient increase with each synchronized burst (Fig. 3B). The amplitude of the transients was $\sim 100 \mathrm{~nm}$. The constant background dopamine level was $\sim 20 \mathrm{~nm}$ (level between bursts in Fig. $3 B$ ). The average dopamine level was $41 \mathrm{~nm}$, slightly higher than the case in which all neurons fired independently at a constant rate of $4 \mathrm{~Hz}$.

As before, $\mathrm{D}_{1}$ receptor occupancy followed a similar time course as the dopamine level (Fig. 3C, red). During bursts, $10-14 \%$ of the $D_{1}$ receptors were activated. During the subsequent pauses, the occupancy was 2-3\%. On average, the occupancy of $\mathrm{D}_{1}$ receptors was $3.7 \%$ compared with $3.5 \%$ in the case of $4 \mathrm{~Hz}$ tonic firing of all neurons.

For $\mathrm{D}_{2}$ receptors, $80 \%$ were occupied as result of the bursts, and $\sim 50 \%$ remained occupied between bursts. Thus, the relative difference in $D_{2}$ receptor activation during bursts and pauses was much smaller than with $\mathrm{D}_{1}$ receptors (Fig. $3 C$, blue). The average occupancy was $66 \%$, $\sim 10 \%$ lower than in the case of tonic activity of all neurons.

The phasic release from bursts and pauses had different impact on $D_{1}$ and $D_{2}$ receptors. Burst firing saturated $\mathrm{D}_{2}$ receptors in large regions of the simulation space. Conversely, as observed previously (Fig. 1), saturation of $D_{1}$ receptors occurred only during the first few milliseconds after release and then only in a limited region around the release sites. Thus, during most of the simulation, occlusion by saturation of $\mathrm{D}_{1}$ receptors did not influence the average occupancy. These results show a strikingly different role of receptor saturation dopamine signaling depending on receptor type.

\section{Reduced $\mathrm{D}_{2}$ receptor occupancy by synchronized burst firing}

The fraction of spontaneous burst firing neurons varies in vivo (Floresco et al., 2003). In addition, the total number of active dopaminergic neurons in ventral tegmental area may be regulated by tonic inhibition from the ventral pallidum (Grace et al., 2007). The firing pattern of neurons in substantia nigra is controlled by globus pallidus (Lee et al., 2004), and the number of active neurons is severely reduced by degeneration in Parkinson's disease (Galvan and Wichmann, 2008).

Therefore, we examined how population size, $N=N_{\mathrm{ph}}+N_{\text {to }}$, and level of synchronous bursts and pauses affected the average dopamine level and average activation of receptors (Fig. 4, solid lines, color indicates population size: blue, $N=100$; green, $N=$ 70 ; red, $N=50$; cyan, $N=30$; and purple, $N=20$ ). The phasic signal consisted of bursts (five spikes at $20 \mathrm{~Hz}$ ), followed by a $1 \mathrm{~s}$ pause; the firing pattern was synchronized between $N_{\text {ph }} \leq N$ neurons. Again both phasic and tonic neurons fired at an average 



Figure 3. Dopamine levels by spontaneous activity of mixed synchronized bursts and pauses $\left(N_{\text {ph }}=50\right)$ and tonic activity $\left(N_{\text {to }}=50\right)$. All neurons have $4 \mathrm{~Hz}$ average firing rate. $A$, Rastogram of the firing patterns. Neurons $1-50$ indicate firing of the synchronized group, whereas neurons 51-100 are not synchronized. B, Average dopamine concentration in the simulation cube. $C$, Relative change in $D_{1}$ and $D_{2}$ receptor occupancy normalized to corresponding tonic activity (Fig. 2). Colors as in Figure 2. Black dashed line indicates the average occupancy by tonic activity.


Figure 4. The effects of phasic population size $\left(N_{\mathrm{ph}}\right)$ and total population size $\left(N=N_{\mathrm{ph}}+\right.$ $N_{\text {to }}$ ). Curves represent different population sizes: blue, 100; green, 70; red, 50; cyan, 30; and purple, 20. Level of dopamine and occupancy of receptors were averaged over space and time for four complete cycles $(5 \mathrm{~s})$. Solid lines indicate the results of synchronized burst firing, whereas dashed lines show the result of synchronized tonic firing. The $x$-axis indicates $N_{\text {ph }}$. When $N_{\text {ph }}=0$, all neurons were assigned tonic firing. In each line, the maximal value of $N_{\text {ph }}$ corresponds to the population size. Left column is normalized to population size. $A$, Average amount of dopamine as a function of number of synchronized neurons. $B$, Mean occupancy of $D_{1}$ receptors. $C$, Mean occupancy of $D_{2}$ receptors.

rate of $4 \mathrm{~Hz}$. Therefore, the total spike count only changed with population size. For each population size, we systematically varied $N_{\mathrm{ph}}$, the number of phasic neurons (Fig. $4: x$-axis indicates $N_{\mathrm{ph}}$; note that $N_{\mathrm{ph}}$ cannot exceed the total number of active neurons).

Average dopamine levels, $\langle C\rangle$, depended strongly on the size of the population but weakly on synchrony (Fig. 4A1,A2). At min- imum synchrony, at which all axons fired randomly and independently, $\langle C\rangle$ varied from $7.1 \mathrm{~nm}$ (20 active neurons) to $38 \mathrm{~nm}$ (100 active neurons). These values agree with previous experimental observations (Ross, 1991; Suaud-Chagny et al., 1992). For small population sizes, synchronous bursts and pauses did not affect $\langle C\rangle$. However, maximum activity $(N=100)$ and synchronized bursts and pauses added $\sim 50 \%$ to the dopamine level. The increase in dopamine levels was not attributable to more dopamine being released, because release probability and average firing rate were constant. Rather, this was an effect of temporal saturation of the dopamine uptake during transients.

$\mathrm{D}_{1}$ and $\mathrm{D}_{2}$ receptors responded differently to synchronized bursts. As expected from our previous results, the average occupancy for $D_{1}$ receptors, $\left\langle D_{1}\right\rangle$, closely followed the progression in average level of dopamine (Fig. 4, compare $B 1, B 2$ with $A 1, A 2$ ).

The average $\mathrm{D}_{2}$ occupancy, $\left\langle\mathrm{D}_{2}\right\rangle$, decreased when the degree of synchronized bursting was increased (Fig. 4C1,C2). Obviously, the magnitude of $\left\langle\mathrm{D}_{2}\right\rangle$ also depended on population size, but a similar relative reduction occurred at different population sizes whenever $N_{\mathrm{ph}}>N_{\mathrm{to}}$, where $N_{\text {to }}$ is the number of nonsynchronized random firing neurons. Compared with random firing at the same activity level, the relative reduction in $\mathrm{D}_{2}$ occupancy was not strongly dependent on the population size (Fig. 4C2). We observed up to $40 \%$ reduction in $\left\langle\mathrm{D}_{2}\right\rangle$ by synchronized burst firing relative to tonic firing at the same activity level. The relative change in average occupancy of the different receptors was even more apparent when we considered the ratio $\left\langle\mathrm{D}_{1}\right\rangle /\left\langle\mathrm{D}_{2}\right\rangle$ (supplemental Fig. S2, available at www.jneurosci.org as supplemental material). Generally, synchronized burst firing resulted in $>50 \%$ reduction in $\left\langle\mathrm{D}_{1}\right\rangle /\left\langle\mathrm{D}_{2}\right\rangle$. The maximal reduction (65\%) occurred when population size was large $(N=100)$, and the reduction was strong even at the smallest population size $(43 \%$ at $N=20)$.

The reduction in average $D_{2}$ receptor occupancy $\left(\left\langle\mathrm{D}_{2}\right\rangle\right)$ was attributable to the combination of high binding affinity and synchronized bursts and pauses. $\mathrm{D}_{2}$ receptors were fully saturated during bursts but were left unoccupied during the subsequent pauses. The result was an overall decrease in average occupancy with synchrony (Fig. 4E).

The effect of synchronized regular firing pattern was also analyzed (Fig. 4, broken lines). Here the changes in average dopamine levels and receptor occupancies as function of synchrony were much lower. This implies that changes in receptor occupancies and dopamine levels are not only attributable to synchrony. Rather, modulation of $\left\langle\mathrm{D}_{2}\right\rangle$ depends on a combination of phasic firing and synchrony.

Intraburst spike frequency, $D_{2}$ receptor saturation, and analysis of spike trains

Spike trains from spontaneously active dopamine neurons are usually characterized in terms of firing rate and fraction of spikes emitted in bursts. The often used 80/160 ms burst criterion defines burst onset by an interspike interval shorter than $80 \mathrm{~ms}$ and burst end by an interval longer than $160 \mathrm{~ms}$ (Grace and Bunney, 1984b). Alternatively, the Poisson surprise criterion defines bursts as groups of spikes with higher rate than expected from a Poisson-type pattern (Legéndy and Salcman, 1985).

This approach to spike trains analysis is arbitrary and often tailored to specific experimental conditions. In this way, results from different experiments, different species, and different firing rates are difficult to interpret and compare. We may also ask whether these measures provide the relevant physiological information.

Our strategy is to use a model based on empirical data to estimate how firing patterns of DA neurons are translated into 

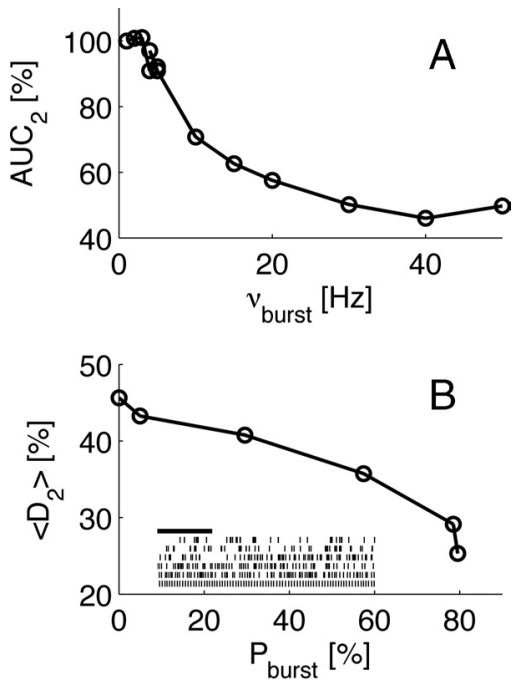

Figure 5. Comparison with standard burst analysis method. $A_{1}$ Total $D_{2}$ receptor activation $\left(\mathrm{AUC}_{2}\right)$ as a function of intraburst frequency. Regular spikes assigned to phasic population $\left(N_{\mathrm{ph}}=50\right)$ and no basal activity $\left(N_{\mathrm{to}}=0\right)$. $\boldsymbol{B}$, Increasing irregularity of spike trains gives gradual increase in average $\mathrm{D}_{2}$ receptors occupancy. Inset, The $20 \mathrm{~s}$ extracts from the spike trains. Scale bar, $5 \mathrm{~s}$.

spatiotemporal activation of postsynaptic DA receptors. In this way, spike trains can ideally be evaluated in terms of postsynaptic receptor activation taking both firing rate and spike pattern into account. To test whether the observed changes in $D_{2}$ receptor occupancy is related to the degree of burst firing, we first varied the interspike frequency of a sequence of five regular spikes. According to our previous results, we expected the effect to be maximized when synchronized burst firing dominates. Therefore, we chose $N_{\mathrm{ph}}=50$ and $N_{\text {to }}=0$ for the test.

We found that the AUC of the $\mathrm{D}_{2}$ receptor occupancy, $\mathrm{AUC}_{2}$, depended crucially on intraburst frequency (Fig. 5A). AUC 2 was maximal at interspike frequencies below $6 \mathrm{~Hz}$. At intermediate interspike frequencies, $\sim 10 \mathrm{~Hz}$, the receptor occupancy declined as function of intraburst frequency. At intraburst frequencies $>20 \mathrm{~Hz}$, the $\mathrm{D}_{2}$ receptor occupancy remained low. Thus, the relative reduction in $\mathrm{AUC}_{2}$ occurred gradually at changes in interspike frequencies from the typical tonic range (Grace and Bunney, 1984a) to the range of frequencies typically observed during bursts (Grace and Bunney, 1984b).

According to the $80 / 160 \mathrm{~ms}$ criterion, the five spikes are categorized as a burst once the interspike frequency is $>12.5 \mathrm{~Hz}$. This is exactly in the range dividing high and low $\mathrm{D}_{2}$ receptor occupancy. Therefore, the $80 / 160 \mathrm{~ms}$ burst criterion correlates with the average $\mathrm{D}_{2}$ receptor levels of our model. The Poisson surprise criterion was not originally developed for dopamine neurons. Here groups of spikes are defined as bursts by the probability of observing the particular group compared with the average firing of the whole spike train. Therefore, we may encounter situations in which the same group of spikes is defined as a burst in one time series (if the average firing is low) but not in other time series. Our results, conversely, predict that only firing rate, synchrony, and background levels determine the average $\mathrm{D}_{2}$ receptor occupancy.

So far we have emulated phasic firing by a sequence of well defined burst epochs, followed by pauses. However, dopamine neurons are characterized by a continuum of firing patterns from regular pacemaker firing to burst firing (Hyland et al., 2002). Typical firing patterns may have $50 \%$ spikes in bursts (Moore et al., 2001; Floresco et al., 2003). We therefore asked whether the observed modulation of $\left\langle\mathrm{D}_{2}\right\rangle$ also applies for more realistic spike trains. To this end, we approximated interspike intervals by gamma distributions and aligned them into spike trains (Miura et al., 2006). This enabled us to generate a family of $50 \mathrm{~s}$ spike trains, all with $4 \mathrm{~Hz}$ average firing rate and with firing patterns ranging from regular (coefficient of variation, 9\%) to irregular (coefficient of variation, $170 \%$ ) (Fig. $5 B$, inset). The fraction of spikes in bursts, $P_{\text {burst }}$, was calculated using the $80 / 160$ ms criterion. $P_{\text {burst }}$ increased from $0 \%$ for the most regular spike train to $80 \%$ for the most irregular. The firing patterns were assigned to $N_{\mathrm{ph}}=50$ synchronized neurons $\left(N_{\text {to }}\right)$.

We estimated $\left\langle\mathrm{D}_{2}\right\rangle$ as function of fraction of spikes in bursts, $P_{\text {burst }}$ (Fig. $5 B$ ). We found that $\left\langle\mathrm{D}_{2}\right\rangle$ was decreasing as the firing patterns became more irregular.

The results were obtained under conditions in which synchronized burst firing was the dominating mode $\left(N_{\text {to }}=0\right)$ and at a specific level of total activity $\left(N_{\mathrm{ph}}=50\right)$. However, we have previously established that the relative change in average occupancy is not sensitive to the total activity at maximal synchrony (Fig. 4C2). The magnitude of the effect will be lower if $N_{\text {to }}$ is raised. However, qualitatively the results will apply provided $N_{\mathrm{ph}}>N_{\text {to }}$ (Fig. 4C1,C2).

Postsynaptic activation by critical saturation of receptors leads to complex response to bursts and pauses

Little is known about the cooperativity of dopamine receptor binding, let alone the relationship between occupancy and postsynaptic signaling. In the sections above, we considered the occupancy of receptors alone. This approach has the advantage of being conservative regarding the number of parameters and assumptions. Furthermore, the occupancy of dopamine receptors can be determined using radiotracers or similar techniques (Farde et al., 1986).

However, the pathways activated in postsynaptic striatal medium spiny neurons (MSNs) are complex (Fernandez et al., 2006; Surmeier et al., 2007), and the postsynaptic effect of dopamine may deviate from the prediction of Equation 12. Therefore, we found it worthwhile to consider the effect of burst firing in an alternative scenario in which the postsynaptic cascade is activated only if a critical fraction of receptors are occupied. We regarded the threshold occupancy as an unknown parameter and tested different values.

Our previous analysis showed that an isolated burst of just two spikes increased the dopamine level from $C_{0}=37 \mathrm{~nm}$ by severalfold to nearly $200 \mathrm{~nm}$ (Fig. 2 B1). If postsynaptic activation occurs only where and when $C(\mathbf{r}, t)>C_{0}$, then the pathway is exclusively sensitive to bursts. On the contrary, pathways activated by thresholds lower than $C_{0}$ would be tonically active except during pauses. The scaling between burst duration and pause duration would be qualitatively similar to $\triangle$ AUC (Fig. 2D1,D2).

However, spontaneous activity with mixtures of tonic and phasic firing lead to radically different activation patterns depending on the particular threshold. We used a mixture of phasic and tonic neurons $\left(N_{\mathrm{ph}}=50, N_{\text {to }}=50\right)$ (same as in Fig. 3 ) and calculated the activity on a postsynaptic pathway assumed to activate at $70 \%$ occupancy of the $\mathrm{D}_{2}$ receptor (Fig. $6 \mathrm{~A}$, blue solid). On average, the activity was lower compared with tonic firing $\left(N_{\mathrm{ph}}=0, N_{\text {to }}=100\right)$ (Fig. $6 \mathrm{~A}$, blue dashed). However, assuming the pathway to be activated at $90 \% \mathrm{D}_{2}$ occupancy, the same firing pattern lead to higher activity on the pathway compared with tonic firing (Fig. $6 \mathrm{~A}$, green).

We then scanned a range of different activation levels and compared the ratio of average activity of the phasic firing pattern $\left(N_{\mathrm{ph}}=50, N_{\mathrm{to}}=50\right)$ with tonic firing $\left(N_{\mathrm{ph}}=0, N_{\mathrm{to}}=100\right)$. The 

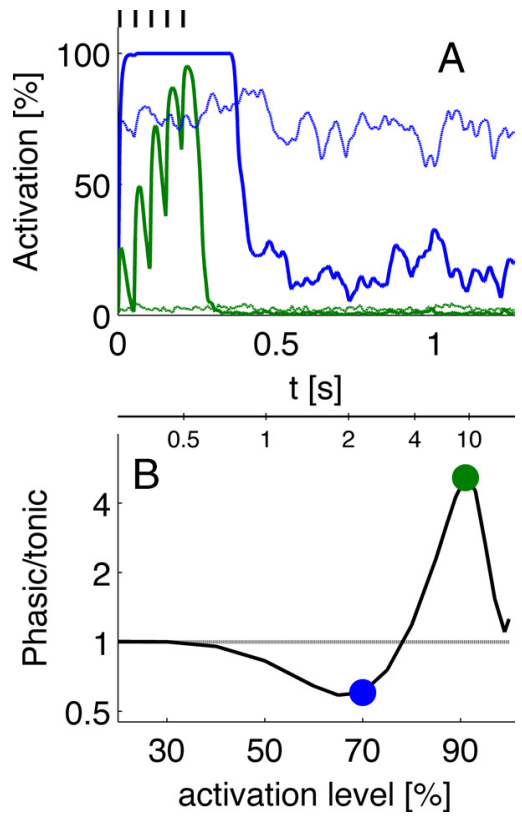

Figure 6. Quantification of postsynaptic activation assuming different thresholds. The results are for mixed spike pattern using same configuration as in Figure $3\left(N_{\mathrm{to}}=50, N_{\mathrm{ph}}=50\right)$. $A$, Solid lines, Activity during different parts of the burst-pause cycle. Blue, $D_{2}$ receptor EC70 (alternatively, $\mathrm{D}_{1}$ receptor $\mathrm{EC} 02$ ); green, $\mathrm{D}_{2}$ receptor $\mathrm{EC} 90$ (alternatively $\mathrm{D}_{1}$ receptor $\left.\mathrm{EC} 10\right)$. The five regular spikes of the burst are indicated above the plot. Dashed lines, Activity during corresponding tonic activity $\left(N_{\mathrm{to}}=100, N_{\mathrm{ph}}=0\right)$. B, Ratio of activation with phasic firing $\left(N_{\mathrm{to}}=50\right.$, $\left.N_{\mathrm{ph}}=50\right)$ compared with tonic firing $\left(N_{\mathrm{to}}=100, N_{\mathrm{ph}}=0\right)$. Dashed gray line indicates when the ratio is 1 (indicating no change). Colored dots indicate the data points corresponding to the curves in $\boldsymbol{A}$. Note logarithmic scale on the $y$-axis in $\boldsymbol{B}$.

result showed a complex interplay between phasic firing and activation at different thresholds. Phasic firing suppressed postsynaptic activation when activation thresholds were $50-75 \% \mathrm{D}_{2}$ receptor occupancy, but enhanced activation with a threshold of $80-95 \% \mathrm{D}_{2}$ receptor occupancy. Outside these regimens, phasic firing had no effect compared with tonic firing (Fig. 6B).

The relationship between activation threshold and the impact of phasic firing can also be expressed for $\mathrm{D}_{1}$ receptors, although the scale is different. In this case, the suppression occurs if the pathway requires $2 \% \mathrm{D}_{1}$ occupancy to be activated, but if activation requires $10 \%$ occupancy, the pathway is facilitated by phasic firing (Fig. $6 B$, top $x$-axis).

\section{Tonic levels influence amplitude and decay of dopamine transients}

In experiments, synchronized activity is typically evoked by electrical stimulations, and volume-averaged dopamine levels are measured using voltammetry or similar techniques (Adams, 1990; Robinson et al., 2008). In such experiments, quantal release from distinct release sites is ignored and background levels of dopamine are usually not determined. The three-dimensional model presented here provides an opportunity to test these assumptions under conditions similar to most investigations in vivo.

We first generated a background dopamine level by assigning random tonic activity to 100 neurons. Variation in background level was achieved by varying the average firing rate of the tonically active neurons from 0 to $16 \mathrm{~Hz}$. We denote the average level of dopamine generated by tonic activity by $C_{0}$. Transients similar to those evoked by stimulated release were then generated by
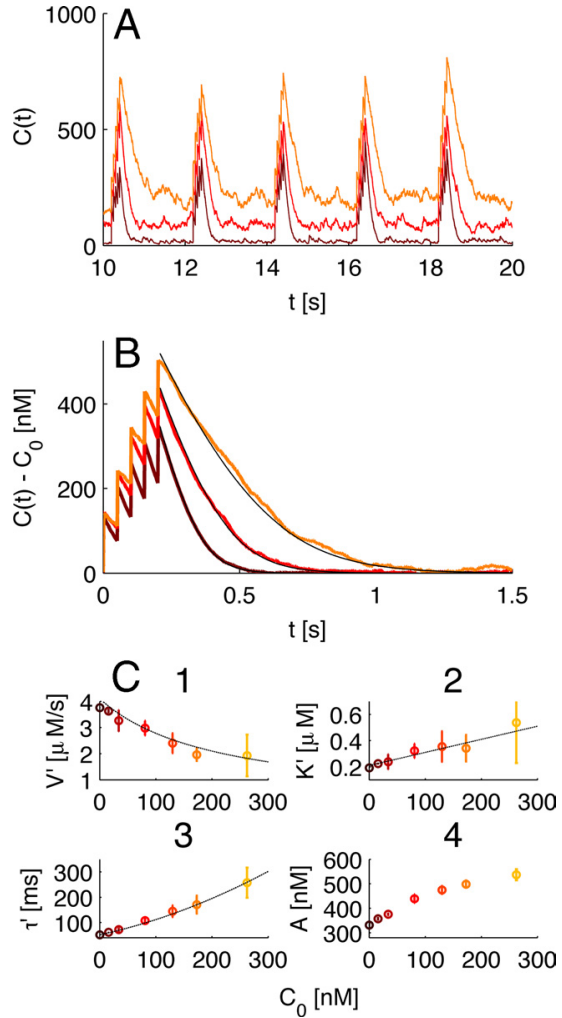

Figure 7. Tonic release influence time development of transients. $\boldsymbol{A}$, Size and shape of transients depends on tonic dopamine release. Transients were evoked by a train of five stimulations at $20 \mathrm{~Hz}$. Different shades of red indicate the basal dopamine level. Dark red has $C_{0}=14$ $\mathrm{nm}$, red has $C_{0}=70 \mathrm{~nm}$, and orange has $C_{0}=230 \mathrm{~nm}$. $B$, Effect of background activity on average uptake kinetics. Average kinetics based on 14 transients as shown in $\boldsymbol{A}$ (same colors). Black lines show the predictions of the Michaelis-Menten model. C, Transient characteristics as function of baseline level. Quantities were found by nonlinear curve fits to the Michaelis-Menten equation; error bars indicate $95 \%$ confidence intervals $(n=5)$. C1, Apparent uptake velocity, $V^{\prime}$. C2, Apparent Michaelis-Menten constant, $K^{\prime}$. (3), Apparent time constant, $\tau^{\prime}$. (4, Amplitude of transients. Black dashed lines show the prediction of Equation 9 (C1), Equation 10 (C2), and Equation 11 (C3).

assigning five synchronized spikes at a rate of $20 \mathrm{~Hz}$ to all dopamine neurons. The tonic activity was unaffected by the stimulus.

This resulted in transients of a magnitude similar to experimental observations (Venton et al., 2003) riding on the basal levels of dopamine (Fig. $7 A ; C_{0}=14 \mathrm{~nm}$, dark red; $70 \mathrm{~nm}$, red; 230 nM, orange). The amplitude and time course of the evoked transients depended on the level of tonic activity. To depict and compare the shape of the transients directly, we averaged 14 transients at different basal levels (Fig. $7 B ; C_{0}$ indicated by the same colors as in $A$ ).

The uptake parameters were determined by nonlinear fits of the Michaelis-Menten equation (Atkins and De Paula, 2002) to the decay profiles of the transients. Mean values and confidence intervals were obtained using five different datasets (each of 14 transients). We denote the observed maximum uptake rate by $V^{\prime}$ and Michaelis-Menten constant by $K^{\prime}$. We found that $V^{\prime}$ decreased as function of $C_{0}$ (Fig. 7C1). At the same time, $K^{\prime}$ increased as a function of $C_{0}$ (Fig. 7C2). We define the apparent time constant as $\tau^{\prime}=K^{\prime} / V^{\prime}$. This parameter was also increasing as function of $C_{0}$ (Fig. 7C3). During the simulations, the intrinsic uptake parameters and release probability were kept constant. The apparent reduction in uptake is attributable to interference of the tonic release (Chen, 2005; Chen and Budygin, 2007). As an 
effect of the apparent reduced uptake, the relative amplitude of the transients also increased (Fig. 7C4).

Drugs often abused recreationally, such as cocaine (Hurd and Ungerstedt, 1989) and amphetamine (Butcher et al., 1988), and therapeutic drugs, such as haloperidol (Reiriz et al., 1994), raclopride (Hertel et al., 1999), and L-Dopa (L-3,4-dihydroxyphenylalanine) (Rodríguez et al., 2007), increase extracellular dopamine levels. The effects of these drugs have been assessed from studies of the kinetics of transients (John and Jones, 2007; Oleson et al., 2009). Because these results may be influenced by $C_{0}$, it is compelling to include the fundamental interaction between the basal level of dopamine and the kinetics of transients into the model. We therefore implemented the modified Michaelis-Menten uptake proposed by Chen (Chen, 2005; Chen and Budygin, 2007) and tested the predictions against the simulations.

The kinetics of evoked transients corresponded very well with the predicted apparent uptake from the model (Fig. $7 B$, black lines). The parameters of the uptake under different conditions were predicted using Equations 9-11 (Fig. 7C, dashed black lines). In another test, the basal level of $N_{\text {to }}=60$ neurons was calculated using Equations 5-7, and transients by $N_{\mathrm{ph}}=40$ neurons were integrated relative to the basal level using modified uptake using Equations 9 and 10. Again, the time evolution was similar to the average dopamine levels obtained from simulations (supplemental Fig. S3, available at www.jneurosci.org as supplemental material). Predictions regarding average occupancy of receptors and average dopamine levels of the simple model and the simulation were similar (supplemental Fig. S4, available at www. jneurosci.org as supplemental material).

\section{Discussion}

\section{Transients map linearly onto receptor occupancy}

We found a linear relation between burst duration and integrated $D_{1}$ receptor occupancy, although $D_{2}$ receptor occupancy was only marginally increased (Fig. 2D1). Pauses, conversely, decreased the relative occupancy of both $\mathrm{D}_{1}$ and $\mathrm{D}_{2}$ receptors linearly (Fig. 2D2). The postsynaptic effect of receptor occupancy depends on the sensitivity of the downstream pathways. If the observed $3-4 \%$ tonic occupancy on $\mathrm{D}_{1}$ receptors is a significant postsynaptic contribution, then our results indicate that pauses also affect $\mathrm{D}_{1}$ receptor signaling.

Conversely, it has been shown that depletion of dopamine reduces spine density in $\mathrm{D}_{2}$ receptor expressing striatopallidal MSNs but not in $\mathrm{D}_{1}$ receptor expressing striatonigral MSNs (Day et al., 2006). This indicates that temporarily reduced activation of $\mathrm{D}_{1}$ receptors during pauses has no influence on dopamineregulated plasticity.

\section{Are synchronized pauses the key to understanding spontaneous firing patterns?}

Phasic firing in spontaneously active dopamine neurons is characterized by bursts of relatively high intensity firing, followed by pauses (Grace and Bunney, 1984b). In the literature, this is often referred to as "burst firing." Our results indicate that modulation of firing patterns from tonic to synchronized bursts and pauses leads to lower average occupancy of $\mathrm{D}_{2}$ receptors compared with $\mathrm{D}_{1}$ receptors (Fig. $4 C$ ). This finding is particularly interesting because it correlates well with the widely used $80 / 160 \mathrm{~ms}$ criterion for bursts (Grace and Bunney, 1984b) (Fig. 5). It is thus possible that firing patterns composed of bursts followed by pauses mediate a different signal than isolated bursts associated with rewards. This is in accord with observations of increased burst firing with stressful stimuli (Moore et al., 2001; Anstrom and Woodward, 2005; Anstrom et al., 2009). In this context, our results indicate that the important signal in "spontaneous burst firing" may be the pauses between bursts.

Firing patterns dominated by synchronized bursts and pauses lead to lower average $D_{2}$ receptor occupancy, whereas the $D_{1}$ receptor occupancy was slightly increased [Fig. 4, compare $B, C$ or see supplemental Fig. S2 (available at www.jneurosci.org as supplemental material)]. Thus, by varying the amount of synchronized bursts, it is possible to regulate average activity on different signaling pathways independently, although they are sensitive to the same neurotransmitter. Clearly, the timeaveraged occupancy of $D_{1}$ or $D_{2}$ receptors does not necessarily present the complete picture of the signaling, but our interpretation of burst firing is also valid if the $\mathrm{D}_{1}$ signaling pathway is particularly sensitive to transient high levels of occupancy during bursts. For example, we observed that bursts induced brief periods of $10 \% \mathrm{D}_{1}$ receptor occupancy (Fig. $3 C$ ).

Our survey of threshold activated pathways showed that spontaneous firing pattern consisting of a mixture of phasic (burst and pauses) and tonic neurons greatly augmented the $D_{1}$ receptor pathway under the assumption that $10 \%$ occupancy was necessary to activate this pathway.

The precise level of synchrony during natural activity is unknown. Hyland et al. (2002) observed that $26 \%$ of cell pairs were correlated on a broad timescale of $\sim 100 \mathrm{~ms}$. This corresponds to bursts and pauses primarily overlapping in $50 \%$ of the neurons. Interestingly, our results predict that synchrony of this scale, with $N_{\text {to }}$ similar to $N_{\mathrm{ph}}$, is on the edge of modulating the $\mathrm{D}_{2}$ receptor occupancy (Fig. 4C). Slight increase in synchrony will lead to reduced $\mathrm{D}_{2}$ occupancy. Evidence from fast-scan cyclic voltammetry suggests that spontaneous 50-100 nM transients occur in regions of nucleus accumbens (Wightman et al., 2007). Our study, along with previous modeling (Venton et al., 2003; Arbuthnott and Wickens, 2007) and experimental (Sombers et al., 2009) studies, suggests that synchronized bursts are necessary for generating transients. According to our simulations, bursts of five spikes at $20 \mathrm{~Hz}$ yield $\sim 100 \mathrm{~nm}$ transients when $50 \%$ of the neurons are synchronized (Fig. $3 B$ ).

Firing pattern and synchrony may also affect estimates of dopamine receptor density from positron emission tomography measurements. Competitive binding of dopamine and radiotracers to dopamine receptors depends on the pattern of dopamine release. Cocaine, and other psychostimulants, make dopamine neurons fire in a more regular manner (Zhou et al., 2006). However, our results indicate that dopamine under these conditions may have higher $\mathrm{D}_{2}$ receptor occupancy. This could lead to lower binding potential for a radiotracer competing for the $\mathrm{D}_{2}$ receptor and therefore influence estimates of, for example, receptor density.

\section{Apparent inhibition by tonic release}

We also tested the validity of simplified models used to determine Michalelis-Menten uptake experimentally (Wu et al., 2001). If the tonic activity is taken into account (Chen, 2005; Chen and Budygin, 2007), the models provide excellent estimates of volume-averaged dopamine levels and receptor occupancies. However, we emphasize that estimates are sensitive to basal activity and that changes in the rate of tonic release, including average firing rate, release probability, and vesicle contents, must be taken into account.

Competitive uptake inhibitors, such as cocaine, methylphenidate, or nomifensene, also change the basal level of dopamine. 
However, the key parameter in the apparent inhibition by tonic release is the difference between tonic release rate $I_{0}$ and intrinsic uptake $V_{\max }$. Assuming that these drugs do not alter $I_{0}$ or $V_{\max }$, changes in apparent $K_{m}$ of the uptake will reflect the action of the inhibitor only.

Our work can be generalized to describe volume transmission of other neurotransmitters if their physiological parameters are known. Three-dimensional models must be used whenever interterminal distance is less than the typical diffusion distance. In the dopamine system, this is not the case. Therefore, the simplified Michaelis-Menten uptake model is a good approximation for modeling dopamine levels and kinetics in striatum.

\section{References}

Adams RN (1990) In vivo electrochemical measurements in the CNS. Prog Neurobiol 35:297-311.

Anstrom KK, Woodward DJ (2005) Restraint increases dopaminergic burst firing in awake rats. Neuropsychopharmacology 30:1832-1840.

Anstrom KK, Miczek KA, Budygin EA (2009) Increased phasic dopamine signaling in the mesolimbic pathway during social defeat in rats. Neuroscience 161:3-12.

Arbuthnott GW, Wickens J (2007) Space, time and dopamine. Trends Neurosci 30:62-69.

Atkins PW, De Paula J (2002) Physical chemistry, Ed 7. New York: Freeman.

Bannon MJ, Michaud RL, Roth RH (1981) Mesocortical dopamine neurons. Lack of autoreceptors modulating dopamine synthesis. Mol Pharmacol 19:270-275.

Bayer HM, Lau B, Glimcher PW (2007) Statistics of midbrain dopamine neuron spike trains in the awake primate. J Neurophysiol 98:1428-1439.

Butcher SP, Fairbrother IS, Kelly JS, Arbuthnott GW (1988) Amphetamineinduced dopamine release in the rat striatum: an in vivo microdialysis study. J Neurochem 50:346-355.

Cagniard B, Balsam PD, Brunner D, Zhuang X (2006) Mice with chronically elevated dopamine exhibit enhanced motivation, but not learning, for a food reward. Neuropsychopharmacology 31:1362-1370.

Carlsson A (2001) A paradigm shift in brain research. Science 294:1021-1024.

Chen KC (2005) Evidence on extracellular dopamine level in rat striatum: implications for the validity of quantitative microdialysis. J Neurochem 92:46-58.

Chen KC, Budygin EA (2007) Extracting the basal extracellular doparnine concentrations from the evoked responses: re-analysis of the dopamine kinetics. J Neurosci Methods 164:27-42.

Cragg SJ, Rice ME (2004) DAncing past the DAT at a DA synapse. Trends Neurosci 27:270-277.

Day M, Wang Z, Ding J, An X, Ingham CA, Shering AF, Wokosin D, Ilijic E, Sun Z, Sampson AR, Mugnaini E, Deutch AY, Sesack SR, Arbuthnott GW, Surmeier DJ (2006) Selective elimination of glutamatergic synapses on striatopallidal neurons in Parkinson disease models. Nat Neurosci 9:251-259.

Doucet G, Descarries L, Garcia S (1986) Quantification of the dopamine innervation in adult rat neostriatum. Neuroscience 19:427-445.

Engert V, Pruessner JC (2008) Dopaminergic and noradrenergic contributions to functionality in ADHD: the role of methylphenidate. Curr Neuropharmacol 6:322-328.

Farde L, Hall H, Ehrin E, Sedvall G (1986) Quantitative analysis of D2 dopamine receptor-binding in the living human brain by PET. Science 231:258-261.

Fernandez E, Schiappa R, Girault JA, Le Novere N (2006) DARPP-32 is a robust integrator of dopamine and glutamate signals. PLoS Comput Biol 2:1619-1633.

Floresco SB, West AR, Ash B, Moore H, Grace AA (2003) Afferent modulation of dopamine neuron firing differentially regulates tonic and phasic dopamine transmission. Nat Neurosci 6:968-973.

Galvan A, Wichmann T (2008) Pathophysiology of parkinsonism. Clin Neurophysiol 119:1459-1474.

Garris PA, Ciolkowski EL, Pastore P, Wightman RM (1994) Efflux of dopamine from the synaptic cleft in the nucleus accumbens of the rat brain. J Neurosci 14:6084-6093.

Gonon F, Burie JB, Jaber M, Benoit-Marand M, Dumartin B, Bloch B (2000) Geometry and kinetics of dopaminergic transmission in the rat striatum and in mice lacking the dopamine transporter. Prog Brain Res 125:291-302.

Goto Y, Otani S, Grace AA (2007) The Yin and Yang of dopamine release: a new perspective. Neuropharmacology 53:583-587.

Grace AA, Bunney BS (1979) Paradoxical GABA excitation of nigral dopaminergic cells: indirect mediation through reticulata inhibitory neurons. Eur J Pharmacol 59:211-218.

Grace AA, Bunney BS (1984a) The control of firing pattern in nigral dopamine neurons: single spike firing. J Neurosci 4:2866-2876.

Grace AA, Bunney BS (1984b) The control of firing pattern in nigral dopamine neurons: burst firing. J Neurosci 4:2877-2890.

Grace AA, Floresco SB, Goto Y, Lodge DJ (2007) Regulation of firing of dopaminergic neurons and control of goal-directed behaviors. Trends Neurosci 30:220-227.

Graybiel AM, Aosaki T, Flaherty AW, Kimura M (1994) The basal ganglia and adaptive motor control. Science 265:1826-1831.

Gubernator NG, Zhang H, Staal RG, Mosharov EV, Pereira DB, Yue M, Balsanek V, Vadola PA, Mukherjee B, Edwards RH, Sulzer D, Sames D (2009) Fluorescent false neurotransmitters visualize dopamine release from individual presynaptic terminals. Science 324:1441-1444.

Hertel P, Fagerquist MV, Svensson TH (1999) Enhanced cortical dopamine output and antipsychotic-like effects of raclopride by alpha2 adrenoceptor blockade. Science 286:105-107.

Hille B (1992) G protein-coupled mechanisms and nervous signaling. Neuron 9:187-195.

Hurd YL, Ungerstedt U (1989) Cocaine: an in vivo microdialysis evaluation of its acute action on dopamine transmission in rat striatum. Synapse 3:48-54.

Hyland BI, Reynolds JN, Hay J, Perk CG, Miller R (2002) Firing modes of midbrain dopamine cells in the freely moving rat. Neuroscience 114:475-492.

John CE, Jones SR (2007) Voltammetric characterization of the effect of monoamine uptake inhibitors and releasers on dopamine and serotonin uptake in mouse caudate-putamen and substantia nigra slices. Neuropharmacology 52:1596-1605.

Lee CR, Abercrombie ED, Tepper JM (2004) Pallidal control of substantia nigra dopaminergic neuron firing pattern and its relation to extracellular neostriatal dopamine levels. Neuroscience 129:481-489.

Legéndy CR, Salcman M (1985) Bursts and recurrences of bursts in the spike trains of spontaneously active striate cortex neurons. J Neurophysiol 53:926-939.

Matsuda W, Furuta T, Nakamura KC, Hioki H, Fujiyama F, Arai R, Kaneko T (2009) Single nigrostriatal dopaminergic neurons form widely spread and highly dense axonal arborizations in the neostriatum. J Neurosci 29:444-453.

Miura K, Okada M, Amari S (2006) Estimating spiking irregularities under changing environments. Neural Comput 18:2359-2386.

Moore H, Rose HJ, Grace AA (2001) Chronic cold stress reduces the spontaneous activity of ventral tegmental dopamine neurons. Neuropsychopharmacology 24:410-419.

Nicholson C (1995) Interaction between diffusion and Michaelis-Menten uptake of dopamine after iontophoresis in striatum. Biophys J 68:1699-1715.

Oleson EB, Salek J, Bonin KD, Jones SR, Budygin EA (2009) Real-time voltammetric detection of cocaine-induced dopamine changes in the striatum of freely moving mice. Neurosci Lett 467:144-146.

Pothos EN, Davila V, Sulzer D (1998) Presynaptic recording of quanta from midbrain dopamine neurons and modulation of the quantal size. J Neurosci 18:4106-4118.

Redgrave P, Gurney K (2006) The short-latency dopamine signal: a role in discovering novel actions? Nat Rev Neurosci 7:967-975.

Reiriz J, Ambrosio S, Cobos A, Ballarín M, Tolosa E, Mahy N (1994) Dopaminergic function in rat brain after oral administration of calciumchannel blockers or haloperidol. A microdialysis study. J Neural Transm Gen Sect 95:195-207.

Rice ME, Cragg SJ (2008) Dopamine spillover after quantal release: rethinking dopamine transmission in the nigrostriatal pathway. Brain Res Rev 58:303-313.

Robinson DL, Heien ML, Wightman RM (2002) Frequency of dopamine concentration transients increases in dorsal and ventral striatum of male rats during introduction of conspecifics. J Neurosci 22:10477-10486. 
Robinson DL, Hermans A, Seipel AT, Wightman RM (2008) Monitoring rapid chemical communication in the brain. Chem Rev 108:2554-2584.

Rodríguez M, Morales I, González-Mora JL, Gómez I, Sabaté M, Dopico JG, Rodríguez-Oroz MC, Obeso JA (2007) Different levodopa actions on the extracellular dopamine pools in the rat striatum. Synapse 61:61-71.

Ross SB (1991) Synaptic concentration of dopamine in the mouse striatum in relationship to the kinetic properties of the dopamine receptors and uptake mechanism. J Neurochem 56:22-29.

Schultz W (1998) Predictive reward signal of dopamine neurons. J Neurophysiol 80:1-27.

Sombers LA, Beyene M, Carelli RM, Wightman RM (2009) Synaptic overflow of dopamine in the nucleus accumbens arises from neuronal activity in the ventral tegmental area. J Neurosci 29:1735-1742.

Suaud-Chagny MF, Chergui K, Chouvet G, Gonon F (1992) Relationship between dopamine release in the rat nucleus-accumbens and the discharge activity of dopaminergic-neurons during local in vivo application of amino-acids in the ventral tegmental area. Neuroscience 49:63-72.

Surmeier DJ, Ding J, Day M, Wang Z, Shen W (2007) D1 and D2 dopaminereceptor modulation of striatal glutamatergic signaling in striatal medium spiny neurons. Trends Neurosci 30:228-235.

Tsai HC, Zhang F, Adamantidis A, Stuber GD, Bonci A, de Lecea L, Deisseroth $\mathrm{K}$ (2009) Phasic firing in dopaminergic neurons is sufficient for behavioral conditioning. Science 324:1080-1084.

Vandecasteele M, Glowinski J, Venance L (2005) Electrical synapses be- tween dopaminergic neurons of the substantia nigra pars compacta. J Neurosci 25:291-298.

Venton BJ, Zhang H, Garris PA, Phillips PE, Sulzer D, Wightman RM (2003) Real-time decoding of dopamine concentration changes in the caudateputamen during tonic and phasic firing. J Neurochem 87:1284-1295.

Wightman RM, Zimmerman JB (1990) Control of dopamine extracellular concentration in rat striatum by impulse flow and uptake. Brain Res Brain Res Rev 15:135-144.

Wightman RM, Heien ML, Wassum KM, Sombers LA, Aragona BJ, Khan AS, Ariansen JL, Cheer JF, Phillips PE, Carelli RM (2007) Dopamine release is heterogeneous within microenvironments of the rat nucleus accumbens. Eur J Neurosci 26:2046-2054.

Wu Q, Reith ME, Wightman RM, Kawagoe KT, Garris PA (2001) Determination of release and uptake parameters from electrically evoked dopamine dynamics measured by real-time voltammetry. J Neurosci Methods 112:119-133.

Zhou Y, Bunney BS, Shi WX (2006) Differential effects of cocaine on firing rate and pattern of dopamine neurons: role of alphal receptors and comparison with L-dopa and apomorphine. J Pharmacol Exp Ther 317:196-201.

Zweifel LS, Parker JG, Lobb CJ, Rainwater A, Wall VZ, Fadok JP, Darvas M, Kim MJ, Mizumori SJ, Paladini CA, Phillips PE, Palmiter RD (2009) Disruption of NMDAR-dependent burst firing by dopamine neurons provides selective assessment of phasic dopamine-dependent behavior. Proc Natl Acad Sci U S A 106:7281-7288. 